\title{
“Gångså Aksårå” : Ekspresi Musikal Dalam Makna Aksara Jawa
}

\author{
Rudi Yatmoko \\ Program Pascasarjana Pengkajian Seni Musik \\ Institut Seni Indonesia Surakarta, Surakarta, Indonesia \\ .Email: rudi.jagad@gmail.com
}

\begin{abstract}
"Gaingså Aksarà" artwork is a musical composition show which expresses aksara Jawa (Javanese alphabet) into music. The background of the creation of "Gängsa A Aksaira" is the existence of aksara Jawa which is unpopular nowadays; its presence is only a brief definition in a learning process. Aksara Jawa has many meanings inside. The purpose of the creation of "Gangsa Aksara" artwork, is to deliver meaning or message which is contained in aksara Jawa and to musically depict the substance of aksara Jawa. The result of deeply observation toward aksara Jawa is that there are four meanings in the core of aksara Jawa, (1) messenger, (2) not deny, (3) fighting, and (4) death. Every meaning has different character. Messenger has the character of being glorious and strong. Fighting has the character of being angry and passionate, while die together has the character of sadness. Those three characters are implemented into music which is united as "Gaingsa Aksaira" artwork. The creation of "Gaingså Aksaira”" uses three steps, they are: preparation, observation, and interpretation. The step of preparation includes data collection about aksara Jawa. Observation step includes observation of ideas and musical material. The step of interpretation includes conception and exploration. Exploration includes sound exploration, exploration of technic, exploration of instrument, play pattern exploration, melody seeking through exploration, drafting composition, sambung rapet drafting, processing of volume and tempo, processing of inception and taste, and evaluation. The result of this thesis and the creation of artwork. "Gangsa Aksara" is expected to be one of many alternatives to make new musical artwork. for students of music creation, especially karawitan students.
\end{abstract}

Keywords: Aksara Jawa; Meaning; Implementation; and Exploration

\begin{abstract}
ABSTRAK
"Gångså Aksårå” adalah pertunjukan komposisi musik yang mengekspresikan aksara Jawa ke dalam sebuah musik. Terciptanya karya "Gångså Aksårå” dilatarbelakangi oleh keberadaan aksara Jawa yang sekarang sudah tidak eksis lagi, kehadirannya hanya sebatas pengertian yang dangkal dalam pembelajaran. Aksara Jawa memiliki banyak makna yang terkandung di dalamnya. Tujuan penyusunan karya "Gangsa Aksara" adalah menyampaikan pesan atau makna yang terkandung di dalam aksara Jawa dan menggambarkan secara musikal substansi aksara Jawa tersebut. Hasil dari pengamatan secara mendalam terhadap aksara Jawa, dapat ditangkap bahwa inti dari aksara Jawa terdapat empat makna, (1) utusan, (2) tidak membantah, (3) adu kekuatan, dan (4) kematian. Setiap makna yang terkandung memiliki karakter yang berbeda-beda. Utusan memiliki karakter agung dan gagah, adu kekuatan memiliki karakter atau sifat nafsu dan amarah, sedangkan kematian dalam adat Jawa memiliki karakter kesedihan. Tiga karakter tersebut diimplementasikan ke dalam sebuah musikal yang menjadi satu kesatuan karya "Gångså Aksårå". Penyusunan karya "Gångså Aksårå" menggunakan tiga tahapan, yaitu: persiapan, observasi, dan tafsir garap. Tahapan dalam persiapan meliputi pengumpulan data-data tentang aksara Jawa. Pada tahap observasi meliputi observasi ide gagasan dan observasi materi musikal. Pada tahap tafsir garap meliputi konsepsi dan eksplorasi. Pada eksplorasi meliputi eksplorasi bunyi, eksplorasi teknik, eksplorasi instrumen, eksplorasi pola permainan, pencarian melodi melalui eksplorasi, penyusunan bagian komposisi, penyusunan sambung rapet, pengolahan volume dan tempo, dan evaluasi. Hasil dari penyusunan karya dan tesis karya seni "Gångså Aksårâ" diharapkan dapat menjadi salah satu alternatif rujukan untuk menyusun karya musik baru bagi mahasiswa penciptaan musik, khususnya mahasiswa karawitan.
\end{abstract}

Kata kunci: Aksara Jawa; Makna; Implementasi; dan Eksplorasi 


\section{A. Pendahuluan}

Aksara Jawa adalah salah satu aksara dari banyak aksara yang ada di Nusantara (Indonesia), yang berasal dari Jawa. Aksara Jawa merupakan alat atau media bagi masyarakat Jawa dalam berbagai bidang seperti pencatatan, transformasi ilmu pengetahuan, yang kini dimaknai sebagai sumber sejarah yang diyakini memuat berbagai informasi dari peristiwa-peristiwa masa lalu (sejarah). Aksara ini memiliki keunikan dari segi bentuk, cara penulisannya dan maknanya. Cara menulis aksara tersebut memperhatikan tebal-tipisnya garis, lengkung huruf, serta makna menjadi sebuah seni (Hapsari Dwi, 2016, hal. 1). Saat ini keberadaan Aksara Jawa semakin ditinggalkan masyarakat pemiliknya.

Aksara Jawa diyakini oleh masyarakat Jawa tercipta atau terlahir dari kisah Ajisaka dan kedua abdi setianya bernama Dora dan Sembada. Cerita - dongeng/legenda tersebut mengakar kuat dalam diri manusia Jawa. Hal tersebut salah satunya terdapat dalam Serat Manikmåyå yang dialih aksara oleh Lasman Marduwiyoto dan Pratomo (Marduwiyoto, 1981, hal. 70-93). Serat Manikmåyå menceritakan kisah Prabu Ajisaka yang melakukan perjalanan dari negeri Atasangin ke Pulau Jawa dan mengalahkan Dewata Cengkar seorang putra Raja Sindhula yang kejam. Akhir cerita menyebutkan Prabu Ajisaka akhirnya diangkat menjadi Raja Medhang Kamulan. Ketika perjalanan itu Prabu Ajisaka menitipkan pusaka kerisnya - disertai pesan kepada Dora dan Sembada agar tidak ada yang mengambilnya kecuali dirinya sendiri. Dora diperintahkan untuk menghadap Ajisaka; supaya Dora mengambil pusaka yang dijaganya bersama dengan Sembada. Dora merasa mendapatkan mandat untuk mengambil pusaka, sedangkan Sembada mendapat perintah untuk tidak memberikan pusaka itu kepada siapapun kecuali Ajisaka. Ajisaka lupa dengan pesan yang diberikan kepada Dora dan Sembada bahwa tidak boleh ada yang mengambil pusaka tersebut kecuali Ajisaka sendiri. Ajisaka mengutus dua Abdinya untuk mengambil pusaka beserta Dora dan Sembada untuk ke Istana Medhang Kamulan, pada akhirnya Sembada tidak menyerahkan pusakanya dengan alasan mempertahankan pesan yang dulu dikatakan oleh Ajisaka, namun Dora tidak memperdulikan pesan tersebut dan diam-diam pergi ke Negara Medhang Kamulan. Ajisaka lupa dengan ucapannya sendiri justru marah dengan Sembada yang tidak mau menyerahkan pusaka, sehingga Ajisaka mengutus Dora untuk kembali dan memerangi Sembada, maka terjadilah perang besar di antara Dora dan Sembada yang mengakibatkan mereka mati bersama. Setelah Ajisaka mengetahui Dora dan Sembada mati, atas kesetiaan dua abdinya 
tersebut maka Prabu Ajisaka mengenangnya dengan membuat Aksara Jawa. Bunyi Aksara Jawa yang dimaksud adalah sebagai berikut.

\section{$H A N A C A R A K A$ \\ $D A T A S A W A L A$ \\ $P A D H A J A Y A N Y A$ \\ $M A G A B A T H A N G A$}

Serat Manikmåyå memaknai setiap baris Aksara Jawa memiliki makna yang saling berkaitan dengan baris-baris berikutnya. "Hånåcåråkà" berarti "ada utusan". "Dåtåsåwålà" berarti "tidak membantah", kemudian "Pådhåjåyanya”" memiliki makna "sama kesaktiannya", dan "Mågåbåthångă" bermakna "mati bersama".

Aksara Jawa terdiri dari 20 huruf yang ditulis dengan simbol sebagai berikut.

\begin{tabular}{|c|c|c|c|c|}
\hline un & १ & 21 & 11 & セி \\
\hline ha & na & ca & ra & ka \\
\hline นด & પી & ฉ & บ1 & Ill \\
\hline $\mathrm{da}$ & ta & sa & wa & la \\
\hline บ1 & ไภ & lR & บUI & I'm \\
\hline $\mathrm{pa}$ & dha & ja & yа & nya \\
\hline fl & 111 & $\mathbf{L}^{\eta} \boldsymbol{l}$ & (nel & $\mathbf{l}^{\prime} \mathbf{1}$ \\
\hline $\mathrm{me}$ & ga & ba & tha & \\
\hline
\end{tabular}

Gambar 1: Simbol aksara Jawa

Hutomo menjelaskan bahwa; Aksara tersebut dimaknai setiap hurufnya hingga mengandung arti wejangan yang utuh. Wejangan bermakna filosofi dari untaian Aksara Jawa versi Kentrung mengandung makna tentang hakikat hidup. Hidup memang dikendalikan oleh sang pencipta (Tuhan), oleh sebab itu manusia harus selalu bersikap patuh dan selalu ingat apa yang seharusnya dilakukan dan dilarang, selalu ingat kepada Tuhannya. Hidup sebaiknya selalu mendahulukan watak utama, selalu berbuat baik dengan sesama. Hal ini akan menjadi bekal kebahagiaan dunia akhirat.

Menurut Halintar Cokro Padnobo sebagaimana yang dikutip dari Soenarno (Padnobo, 2016, hal. 55), bahwa arti dari Aksara Jawa pada dasarnya tidak menceritakan tentang kisah dua abdi yang mati bersama. Bahwa batin dan pikiran wajib dimengerti dan diketahui karena sangat berguna, berwujud catatan yang tidak boleh sampai tercecer, tindakan atau gagasan yang baik patut untuk dicontoh, dunia ini harus saling menjaga dan saling bergotong royong, dan tidak boleh hidup egois serta mementingkan diri pribadi. Dengan kita bergotong-royong maka kita akan hidup damai dan saling bertoleransi satu dengan yang lain.

Pemaknaan-pemaknaan di atas mengerucut pada dimensi yang sama tentang Aksara Jawa, dapat disimpulkan di mana Aksara Jawa mengandung makna tentang kehidupan manusia. Manusia dalam konteks Aksara Jawa ; hidup di dunia tidak terlepas dari sebuah utusan dari Tuhan, dengan kekuatan yang diberikanNya manusia wajib menjaga toleransi dan kebersamaan sesama makhluk 
hidup, karena kehidupan tidak akan pernah lepas dari sebuah kematian.

Aksara Jawa tidak berdiri sendiri tetapi terdapat perangkat simbol yang dalam tradisi Jawa disebut dengan sandhangan dan pasangan. Secara harfiah sandhangan bermakna pakaian. Pakaian inilah yang nantinya menentukan Aksara Jawa yang "telanjang” (dalam istilah Jawa disebut dengan nglegena) menjadi bermakna dalam konteks penyampai pesan. Sandhangan berjumlah 12 aksara atau huruf vokal, yang makna artinya bahwa hidup yang mulai berwujud makhluk di dunia ini selalu "menyandang" tetapi bukan berarti pakaian, melainkan menyandang rasa (Endraswara, 2006, hal. 48). Dua belas sandhangan tersebut tersimbol di bawah ini.

\begin{tabular}{|c|c|c|c|c|c|}
\hline $\begin{array}{c}\text { Nama } \\
\text { Sandhangan }\end{array}$ & $\begin{array}{l}\text { Alssara } \\
\text { Jawa }\end{array}$ & Keterangan & $\begin{array}{c}\text { Nama } \\
\text { Sandhangan }\end{array}$ & $\begin{array}{l}\text { Alssara } \\
\text { Jawa }\end{array}$ & Keterangan \\
\hline Wulu & o & tanda vokali & Wignyan & 3 & tanda gantikonsonan $h$ \\
\hline Suku & U & tanda vokalu & Cecak & • & tanda gantikonsonanng \\
\hline Taling & 川 & tanda vokal é & Pangkon & & tanda penghilang vokal \\
\hline Pepet & 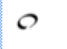 & tanda vokale & Péngkal & اת & tanda gantikonsonan ya \\
\hline Taling Tarung & m 2 & tanda vokal 0 & Cakra & $\circlearrowleft$ & tanda gantikonsonanra \\
\hline Layar & / & tanda gantikonsonanr & Cakra keret & \& & tanda gantikonsonanre \\
\hline
\end{tabular}

Gambar 2: Simbol sandangan aksara Jawa (Abikusna, 1996:105)

Pasangan aksara Jawa tersebut melukiskan bagaimana sifat manusia dalam kehidupan sehari-hari. Ada sifat manusia yang bersifat jujur, tulus, pemarah, rendah hati, dan lain sebagainya. Oleh karena itu, jika digabungkan dengan aksara Jawa di atas, maka orang hidup harus berbuat baik dengan sesama, tidak boleh egois, dan harus saling membantu.

\begin{tabular}{|c|c|c|c|c|}
\hline ... ح & $\ddot{\triangleleft}$ & $\dddot{c}$ & วั & ав, \\
\hline $\mathrm{Ha}$ & $\mathrm{Na}$ & $\mathrm{Ca}$ & $\mathbf{R a}$ & Ka \\
\hline$\ddot{c}$ & & $\ldots$ 小 & "ִü & ${ }_{a} a_{\text {, }}$ \\
\hline Da & $\mathrm{Ta}$ & Sa & $\mathbf{W a}$ & La \\
\hline الح & $\dddot{\omega}$ & $G$ & aับ & إلهُ \\
\hline $\mathrm{Pa}$ & Dha & Ja & $\mathrm{Ya}$ & Nya \\
\hline 光 & ต่กก & CB & (0) & aา \\
\hline Ma & Ga & Ba & Tha & Nga \\
\hline
\end{tabular}

Gambar 3: Simbol pasangan aksara Jawa

(Abikusna, 1996:104)

Pasangan dalam aksara Jawa khususnya pada kasus ini tidak menjadi penting kehadirannya, karena Hånåcåråkå sendiri sudah memiliki makna tersendiri tanpa hadirnya sebuah pasangan. Hadirnya pasangan selalu ada dalam penulisan aksara Jawa pada umumnya.

Makna-makna aksara Jawa di atas yang memaknai aksara Jawa sebagai sebuah; utusan, saling bertengkar, sama kesaktiannya, dan mati bersama kiranya menarik untuk diangkat oleh pengkarya sebagai ide. Ide inilah yang nantinya diungkap dalam medium musik. Hal ini dilakukan karena berpijak pada keresahan yang ada terkait kondisi aksara Jawa sekarang.

Ada banyak cara untuk melestarikan aksara Jawa seperti yang dilakukan kota-kota berbasis kebudayan Jawa seperti Yogyakarta dan Surakarta (Solo). Aksara Jawa di dua kota tersebut sekedar digunakan dalam penulisan 
nama jalan, nama gedung, atau tempat-tempat wisata lainnya. Hal ini agar masyarakat Jawa tidak melupakan warisan leluhur yang harusnya masih tetap berfungsi dengan baik untuk kehidupan komunikasi sehari-hari atau sekedar simbol yang memperkuat kesan Jawa saja.

Pengkarya merasa perlu "melakukan sesuatu" dengan hal tersebut karena mengingat aksara Jawa merupakan sebuah jati diri yang selalu melekat dengan orang Jawa, aksara tersebut tidak sekedar aksara yang diciptakan hanya sebagai sarana komunikasi seperti halnya alfabet, tetapi aksara Jawa memiliki makna yang terkandung di dalamnya. Pengkarya ingin mengungkap makna di dalam aksara Jawa melalui kesenian dengan kemasan pertunjukan musik komposisi. Hasil yang diharapkan melalui keterlibatan dalam pertunjukan, baik pemain maupun penonton dapat mengenal dan memahami makna di dalam aksara Jawa.

\section{B. Metode}

Pada tahap ini seniman penyusun mulai memikirkan alat atau instrumen yang digunakan untuk dapat mendukung gagasan isi yang telah disusun. Pencarian dan penentuan instrumen terus dilakukan, dan pada akhirnya seniman penyusun menentukan alat yang digunakan dengan memikirkan garap yang dilakukan pada alat tersebut sesuai dengan suasana yang diungkapkan (Sukerta, 2011, hal. 69). Adapun karya ini tercipta melalui tahapan kerja sebagai berikut.

\section{Observasi}

Tahapan ini sangat membantu untuk mengumpulkan beberapa data yang belum didapatkan mengenai tentang aksara Jawa. Data tersebut sangat dibutuhkan dalam terciptanya karya ini nanti guna digunakan agar karya yang diciptakan dapat dipertanggungjawabkan. Observasi yang telah dilakukan adalah membaca dan memahami hakikat aksara Jawa berserta pemaknaannya dalam buku. Buku-buku yang dimaksud dipahami dan kemudian dikerucutkan pada makna pada masing komposisi yang digarap pada karya "Gångså Aksårå".

\section{Tafsir garap}

Proses penggarapan komposisi musik merupakan tahapan yang paling penting dalam menyajikan sebuah karya musik yang berkualitas, di dalam penggarapan meliputi beberapa aspek yaitu:

\section{Tahap Konsepsi}

Konsepsi merupakan tahapan di mana pengkarya menyusun objek, inspirasi, 
khayalan, ide-ide, kemudian merancangnya dalam sebuah konsep penciptaan, sesuai dengan media yang digunakan. Hal ini dilakukan pengkarya dengan membuat polapola ritmik dan melodi yang digunakan nantinya sebagai embrio karya “Gångså Aksårå".

\section{Tahap Penggarapan}

Eksplorasi dalam Tesaurus Bahasa Indonesia: investigasi, pencarian, pendalaman, penelitian, penggalian, pengkajian, penjajahan, riset, studi. Tahapan di mana pengkarya melakukan penjajakan lebih mendalam atas ide-ide dan materi-materi yang ada pada konsep penciptaan, sehingga memperkuat daya kreativitas. Dalam proses eksplorasi pengkarya menghadirkan berapa pola, melodi, serta beberapa tekhnik, kemudian dikembangkan sesuai dengan kebutuhan, dan menyesuaikan instrumen yang digunakan.

\section{Hasil dan Pembahasan}

\section{Gagasan}

Hånåcåråkå merupakan sebuah aksara yang berkembang di Jawa. Aksara tersebut merupakan perkembangan dari aksara Kawi yang merupakan salah satu turunan dari aksara Brahmi. Pada masa periode Hindu-Buddha, aksara tersebut digunakan dalam literatur keagamaan dan terjemahan Sanskerta yang 54 biasa ditulis dalam naskah daun lontar. Bentuk aksara Kawi berangsur-angsur menjadi lebih Jawa, tetapi dengan otografi yang tetap. Pada abad ke-17, tulisan tersebut berkembang menjadi bentuk modernnya yang dikenal sebagai Carakan atau Hånåcåråkå berdasarkan lima aksara pertamanya. Aksara Jawa tersebut menggunakan sistem penulisan Abugida yang memiliki arti ditulis dari kiri ke kanan.

Aksara Jawa dibagi beberapa jenis berdasarkan fungsinya. Aksara dasar terdiri dari 20 suku kata yang menjadi dasar untuk menulis bahasa Jawa, sedangkan aksara yang lain terdiri dari aksara swårå, tanda baca, dan angka Jawa. Dalam penulisan aksara Jawa terdapat diakritik atau yang disebut dengan sandhangan, berfungsi untuk mengubah konsonan pada huruf aksara.

Terbentuknya aksara Jawa tidak terlepas dari sebuah cerita dan makna di dalamnya. Setiap aksara dapat memiliki makna tersendiri, namun juga dapat dimaknai pada satu kalimat atau satu baris aksara Jawa. Dalam karya “Gångså Aksårå” ini mencoba mengimplementasikan makna yang terkandung dalam cerita lahirnya aksara Jawa ke dalam bentuk musikal.

Pada karya ini pengkarya berusaha menafsirkan sebuah kata-kata menjadi sebuah musik. Kata yang dimaksud merupakan kata yang menjadi sebuah makna yang terkandung 
pada aksara Jawa. Makna yang terlalu luas membuat pengkarya membatasi pada sebuah frame yang digunakan untuk acuan dalam membuat karya ini. Makna yang digunakan adalah makna dalam setiap barisnya (Hånåcåråkå, Dåtåsåmålå, Pådhåjåyånyå, dan Mågåbåthångå), jadi tidak diambil makna perhuruf atau per-katanya. Makna tersebut sangat berkaitan dengan cerita Ajisaka yang merupakan cerita dibalik lahirnya aksara Jawa. Oleh karena itu cerita Ajisaka tersebut menjadi sebuah dasar dalam membuat karya ini. Aksara Jawa tercipta untuk mengenang kesetiaan abdi Ajisaka, yaitu Dora dan Sembada, maka dibuatkanlah sebuah aksara Jawa. Hånåcåråkå memiliki sebuah arti ada utusan, hal tersebut berkaitan dengan cerita Ajisaka ketika mengutus abdinya untuk mencari Dora dan Sembada yang sedang menjaga pusakanya, makna "ada utusan" menjadi sebuah dasar dalam bagian karya pertama.

Karya "Gångså Aksårå" dipentaskan di Teater Kecil ISI Surakarta. Tempat tersebut menjadi lokasi pementasan karya ini, karena pada dasarnya tempat pementasan karya ini bebas di mana saja, tetapi jika dipentaskan di tempat umum contohnya di pinggir sungai, justru akan menimbulkan penafsiran ganda pada audien, penonton tentunya akan mencoba menghubungkan aksara Jawa dengan tempat pinggir sungai tersebut. Untuk menghindari hal itu, maka pengkarya menempatkan sajian ini pada tempat yang memang notabene digunakan untuk sebuah pertunjukkan. Hal itu juga mendukung penonton akan lebih khidmat dalam memaknai sajian karya ini.

Unsur artistik juga digunakan dalam mendukung karya ini. Artistik merupakan segala unsur kreasi seni pendukung pementasan yang menjadikan panggung lebih hidup. Unsur artistik adalah salah satu unsur penting dalam suatu pertunjukan seni, apakah itu teater, musik, tari, drama atau film. Unsur artistik meliputi beberapa unsur di antaranya tata panggung, tata cahaya, tata musik, tata suara, tata rias, dan busana. Tata panggung berhubungan dengan penataan tampilan atau pemandangan di panggung yang disesuaikan dengan garap yang dimunculkan pada karya musik. Oleh karena itu, pengkarya juga membangun unsur artistik guna membantu menjelaskan makna yang disampaikan dari karya ini.

Bagian pertama pada karya ini adalah "Cundhåkå" yang dapat diartikan sebagai utusan. Pada bagian ini merupakan sebuah implementasi dari makna yang terkandung pada kalimat Hånåcåråkå dan Dåtåsàwålå. Seorang yang menjadi utusan atau duta tentunya adalah seorang yang dipercaya dan tidak membantah. Seorang utusan tentunya 
memiliki karakter yang tegas, berwibawa, dapat menyelesaikan masalah, agung, dan gagah. Karakter tersebut yang mendasari "cundhåkå" menjadi sebuah musik.

"Cundhåkå" terbentuk berdasarkan karakter-karakter yang ada pada seorang utusan, oleh karena itu kesan yang dibangun dalam bagian ini adalah kesan agung, wibawa, dan seperti yang sudah dijelaskan di atas. Pengkarya berusaha menafsirkan makna yang terkandung dalam Hånåcåråkå tersebut menjadi sebuah karya musikal. Unsur artistik juga dibangun dalam mendukung suasana pada bagian ini, seperti menggunakan kostum yang sederhana dan berwibawa. Tata cahaya juga diatur sedemikian rupa agar mendukung efek yang tegas dan berwibawa. Tata suara juga sangat diperhatikan pada bagian ini, sebagaimana diatur dengan mixing yang tepat supaya instrumen satu dengan yang lain tidak saling tumpang tindih, tetapi dapat menjadi satu kesatuan suara yang menyatu dalam satu ruangan tersebut.

Bagian pertama ini diciptakan untuk mepresentasikan cerita yang tergambar dalam Ajisaka, sehingga audien dapat merasakan suasana kewibawaan seorang utusan, keagungan menjadi seorang duta, dan ketegasan menjadi seorang utusan. Melalui musik, cerita tersebut direalisasikan secara implisit, dengan menekankan kesan-kesan seperti yang sudah dijelaskan di atas.

Bagian kedua dengan judul "Pralågå" yang memiliki arti sama kuatnya atau adu kekuatan. Dalam bagian kedua ini mengimplementasikan elemen makna dari aksara Pådhåjåjånyå ke dalam karya musik. Pådhåjåyånyå memiliki makna sama kekuatanya. Pertengkaran dua orang yang sama kuatnya atau sama saktinya. Jika ditarik pada cerita Ajisaka, makna kalimat tersebut merupakan penggambaran pertengkaran hebat di antara Dora dan Sembada yang merupakan abdi dari Ajisaka, Dora dan Sembada memiliki kekuatan yang sama hebatnya. Dasar mereka berkelahi adalah sebuah kebenaran yang saling diperdebatkan, Dora memiliki kebenaran dalam sudut pandangnya sedangkan Sembada juga memiliki kebenaran pada sudut pandangnya, sehingga menimbulkan pertengkaran yang hebat, dan pada akhirnya keduanya mati bersama.

Bagian dua ini mewujudkan makna cerita tersebut ke dalam musikal, bagaimana peperangan itu terjadi, betapa hebatnya jika ada dua orang yang sama hebatnya bertarung, sehingga mengakibatkan mereka mati bersama. Musikal yang dibangun merepresentasikan sebuah pertarungan hebat yang memiliki karakter sereng, nafsu, amarah, greget, tegang, banter, menakutkan, dan gagah sehingga dapat mewujudkan musik yang 
mepresentasikan sebuah peperangan. Selain musikal yang utama dalam membangun suasana tersebut, maka artistik juga menyesuaikan untuk mendukung suasana tersebut. Seperti halnya tata cahaya dibuat kesan tegang dan sereng dengan mendominasi warna merah untuk melambangkan amarah dan nafsu, sehingga dapat mendukung membangun suasana tegang.

Bagian tiga dengan judul "Pralåyå" yang dapat diartikan mati, dapat mewakili pada aksara Mågåbåthångå yang memiliki mati atau mati bersama. Dalam aksara tersebut menceritakan kematian dua abdi Ajisaka, yaitu Dora dan Sembada, kematian keduanya disebabkan mereka saling memiliki dasar yang kuat dalam menjaga pusaka yang dititipkan oleh Ajisaka. Dora yang diutus Ajisaka menjelaskan kepada Sembada jika pusakanya diminta untuk diserahkan ke Kerajan Mendhang Kamulan, namun Sembada bersih kukuh untuk tetap menjaga pusaka tersebut dan sesuai dengan amanat yang dulu Ajisaka berikan, yaitu jangan memberikan pusaka tersebut selain Ajisaka sendiri yang mengambilnya. Maka dari, itu terjadilah peperangan hebat, dikarenakan Dora dan Sembada memiliki kekuatan yang sama kuat dan sama saktinya, maka mereka berdua mati bersama. Kematian kedua abdi tersebut menimbulkan duka yang sangat mendalam bagi Ajisaka. Kesedihan dalam kematian tersebut dipresentasikan dalam bagian tiga ini menjadi sebuah karya musik.

Pralåyå yang bertolak pada cerita kematian Dora dan Sembada, maka dalam bagian ini didominan dengan kesan kesedihan yang mendalam. Kesedihan yang dimaksud adalah kesedihannya orang yang meninggal dunia. Karakter yang digunakan dalam membangun kesedihan tersebut adalah; susah, ngondhok-ondhok, sungkaiwå, mangungkung, gundah gulana, dan èmeng. Penguat suasana sedih didukung dengan artistik. Kesan sedih didukung dengan lighting yang sedikit redup dan bertema soft, sehingga dapat mendukung kesan sedih dalam sajian karya ini.

\section{Garapan}

Karya musik "Gångså Aksårå" merupakan komposisi musik yang menggunakan mediumnya adalah gamelan gaya Surakarta. Gamelan Jawa khususnya gaya Surakarta dipilih karena pengkarya menguasai gamelan Jawa gaya Surakarta dan gamelan dapat mewakili sebuah identitas orang Jawa, karya musik yang diangkat dari aksara yang tumbuh berkembang di Jawa menjadi landasan utama dalam pemilihan instrumen yang digunakan, serta mempertimbangkan suasana yang dibangun dalam garap musikalnya. Gamelan juga dipadukan dengan instrumen- 
instrumen yang lain, sepertihalnya; saxophone, kecapi, piano, dan cello. Hal tersebut untuk mendukung suasana yang ingin dicapai dalam setiap bagian musiknya.

Penggarapan musik dalam karya ini memadukan antara tekstual dan musikalitas, hal yang tidak dapat dijelaskan dengan bunyi didukung dengan teks vokal yang tersirat maupun tersurat. Kehadiran vokal dalam beberapa bagian tentunya sangat penting untuk mejelaskan makna yang diinginkan. Dalam bagian tertentu justru menekankan pada musikal untuk menjelaskan suasana yang dimaksud. Dalam contoh; pada bagian dua mendominasi karya dengan musikal, dikarenakan suasana yang dibangun merupakan suasana amarah, sehingga sebuah teks kurang mendukung untuk konteks ini. Bagian yang memiliki suasana amarah diwakili dengan instrumen pencon yang fungsinya untuk membangun suasana sereng.

Perpaduan antara instrumen gamelan dan instrumen musik Barat menghasilkan sebuah warna suara yang baru dan membuat karya menjadi lebih kompleks dalam hal garap. Tentunya tidak mudah menggabungkan warna suara gamelan dengan non gamelan, di sisi lain kedua jenis instrumen tersebut memiliki tangga nada yang berbeda, meskipun terkadang dapat dituning dan disamakan dengan tangga nada gamelan namun justru hadirnya nada-nada baru yang di gamelan tidak ada membuat karya ini menjadi lebih indah.

Penggarapan vokal tidak terlepas dari cakepan, céngkok, dan lagu. Pemilihan teks atau diksi yang digunakan sangat diperhatikan, sehingga dapat merepresentasikan apa yang terkandung dalam aksara Jawa. Céngkok yang digunakan disesuaikan dengan tema yang diangkat, setiap bagian memiliki karakter yang berbeda-beda jadi setiap céngkok yang diciptakan dapat membangun karakter yang diinginkan.

Bagian komposisi pertama digarap dengan percampuran instrumen Barat dan vokal, yang didominasi dengan instrumen piano dan beberapa vokal. Piano memainkan nada-nada yang terkadang berlaras pélog dan sléndro, tetapi juga menyisipkan nada-nada diatonis untuk memberi warna pada lagu yang diciptakan. Vokal koor dapat mendukung karakter menjadi agung, seperti halnya pada karawitan garap bedhayan yang mengedepankan vokal koor. Bedhayan dengan vokal yang bersama ditambah céngkok yang digunakan sederhana dan lugu, membuat karakter bedhàyå menjadikan agung. Hal tersebut pencipta mencoba mengimplementasikan konsep yang terdapat pada bedhayan ke dalam bagian "Cundhåkå".

Karakter agung dapat terbangun berdasarkan vokal yang ditembangkan secara 
koor dengan céngkok-céngkok yang sederhana dan lugu, dipadukan dengan piano yang memainkan melodi-melodi dengan tegas sehingga mampu menghasilkan karakter atau suasana yang agung dan berwibawa. Teks yang digunakan dalam vokal juga dibuat sederhana, tidak menggunakan bahasa yang terlalu halus, sehingga makna yang terkandung diharap dapat tesampaikan dengan baik dan benar.

Pada bagian komposisi kedua menggarap dengan instrumental yang berjenis pencon. Instrumen pencon dalam karawitan gaya Surakarta menghasilkan bunyi yang dapat membangun karakter sereng. Hal tersebut terbukti pada iringan pakeliran instrumen pencon menjadi titik tumpu dalam membuat suasana sereng, dalam contoh; pada adegan perang suasana dibangun dengan tabuhan kenong, kempul, kethuk, dan gong. Instrumen tersebut dengan garap jalinan melodi suasana sereng dapat dibangun, contoh kongkritnya pada adegan perang dalam garap sirepan, instrumen yang tetap memainkan nada-nadanya hanya instrumen-instrumen tersebut, selain merupakan instrumen struktural tetapi juga termasuk instrumen pembentuk karakter sereng.

Konsep yang terdapat pada iringan pakeliran tersebut mencoba diterapkan pada bagian dua ini, dengan mengolah instrumeninstrumen pencon dan menambahkan bonang penembung serta engkuk dan kemong, diharapkan dapat membangun suasan sereng. Instrumen pencon juga memiliki range atau jarak nada yang luas, dengan memadukan instrumen bonang penembung sampai bonang penerus menghasilkan range yang sangat lebar, hal tersebut sangat mendukung dalam pengolahan nada-nada yang digunakan untuk mendukung suasana sereng.

Bagian bagian koposisi kedua ini menggarapa berdasarkan makna yang terkandung dalam aksara Pådhajååanyå, seperti yang sudah diceritakan bahwa Dora dan Sembada sedang berperang mereka mengadu kekuatan mereka masing-masing dengan dasar yang sama kuatnya, sehingga peperangan terjadi begitu dasyat dan tidak dapat dihindari. Akibat peperangan tersebut maka mereka menjadi mati bersama yang kemudian diimplementasikan dalam bagian tiga.

Bagian komposisi ketiga dengan judul "Pralåyå" menggarap dengan dasar makna yang terkandung pada aksara mågåbåthångå yang dapat diartikan mati bersama, dengan pijakan makna tersebut maka komposisi musikal ini menggarap dengan suasana kesedihan orang meninggal. Suasana kesedihan dibangun dengan instrumen yang memiliki karakter lembut dan mendayu-dayu yang terdapat pada instrumen rebab, ditambah dengan vokal untuk menguatkan dalam 
pengungkapan kesedihan, kesedihan dapat dibangun dengan meyajikan nada-nada pengembangan dari nada minir.

Dalam bagian ini mengeksplor beberapa instrumen rebab dengan jalinan-jalinan melodi yang harmoni, terkadang membunyikan nada yang sama secara bersama-sama, tetapi terkadang juga membunyikan nada-nada yang berbeda yang masih satu harmoni. Kesedihan juga dibangun dengan menggunakan cakepan vokal yang persentatif, sehingga audien dapat mengetahui bahwa dalam komposisi musik ini mempresentasikan kesedihan dalam kematian. Vokal mengolah céngkok-céngkok yang bernuansa kesedihan, dengan menggunakan laras pélog dalam karawitan gaya Surakarta. Penggarapan céngkok-céngkok vokal di sini menggunakan nada-nada yang jarang ditemui dalam garap karawitan Jawa secara konvensional, contohnya terdapat nada 1, 4, 7 yang digabungkan dalam satu sajian garapan vokal dan rebab.

\section{Deskripsi Sajian}

\section{1) “Cundhåkå"}

Komposisi "Cundhåkå" terdiri dari delapan bagian, berikut dijabarkan masingmasing bagian tersebut.

\section{a. Bagian Satu}

Bagian ini diawali oleh pemain vokal putra dan putri satu persatu berjalan memasuki stage pertunjukan dengan menyajikan vokal secara bersama-sama tanpa diiringi menggunakan alat musik. Berikut di bawah ini notasi vokal.

$$
\begin{aligned}
& \text { Vokal Pa Koor } \\
& \begin{array}{lllllll}
6 & 3 & 4 & 1 & 7 & 5 & \| \\
\text { Hem } & \text { bo } & \text { ba } & \text { bi } & \text { bu } & \text { ba }
\end{array}
\end{aligned}
$$

Vokal Pi Koor

$$
\begin{aligned}
& \begin{array}{lllllllllllllll}
5 & 6 & 6 & \cdot & 1 & 3 & 3 & \cdot & 4 & 5 & 3 & . & 4 & 2 & 1
\end{array} \\
& \text { Cundhåkå sa-da-må u-tå-må ak-så-rå }
\end{aligned}
$$




$\begin{array}{llllllllllll}3 & 2 & 3 & 3 & 3 & 2 & 3 & 3 & 1 & 3 & 1 & \\ A-m e-m u-~ & j i & m r i b & r a-b a- & y u & s e- & s a- & m i\end{array}$

Vokal Pi 2

$$
\begin{array}{lllllllllll}
6 & 5 & 6 & 6 & 6 & 5 & 6 & 6 & 5 & 5 & 5 \\
A-m e-m u-j i & m r i h & r a-b a- & y u & s e- & -s a- & m i
\end{array}
$$

Vokal Pi Koor

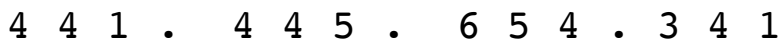

$$
\begin{aligned}
& \text { Hånå-cå cå-rå-kå då-tå-så så-wå-lå }
\end{aligned}
$$

Vokal Pi 1

\section{$\begin{array}{lllllllllll}2 & 3 & 3 & 3 & 2 & 5 & 5 & 5 & 3 & 3 & 1\end{array}$}

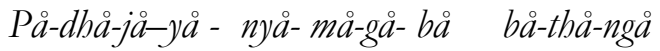

Vokal Pi 2

$$
\begin{aligned}
& \begin{array}{lllllllllll}
6 & 1 & 1 & 1 & 6 & 3 & 3 & 3 & 1 & 6 & 5
\end{array}
\end{aligned}
$$

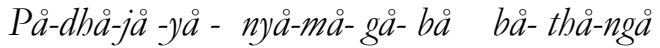

\section{b. Bagian Dua}

Bagian ini diawali dengan pukulan gong gedé, piano, dan cello yang di bunyikan secara bersama-sama tiga kali pukulan yang setiap jeda pukulan ini dimasuki oleh vokal koor putra dan putri, setelah pukulan yang ke tiga diisi oleh vokal tunggal putra, kemudian yang terakhir vokal koor bersama dengan gong, piano dan cello. Notasi sebagai berikut.

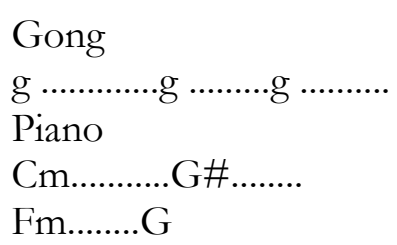


Cello 6...

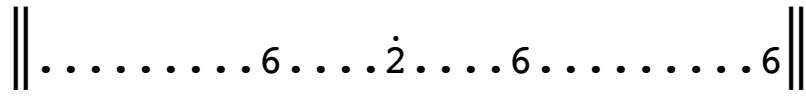

Vokal Putra Koor

$\begin{array}{llllllllllll}\dot{3} & 2 & \dot{3} & \dot{1} & \dot{3} & \dot{2} & \dot{3} & \dot{4} & 5 & 6 & \dot{1} & \dot{2}\end{array}$

Sasmita-né was-pa-dak-nå ha-na-ni-rå

Solo vokal Putra

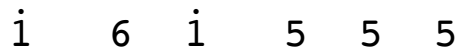

Jang-ka-né jen-jem-ing

Koor

$\begin{array}{llll}i & \dot{2} & 7 & \text { (i) }\end{array}$

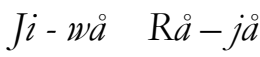

Vokal Putri Koor

$\begin{array}{llllllllllll}\dot{5} & \dot{4} & \dot{5} & \dot{3} & \dot{5} & \dot{4} & \dot{5} & \dot{6} & \dot{2} & \dot{3} & \dot{1} & \dot{1} 7\end{array}$

Sas-mi-ta-né was-pa-dak-nå ba-na-ni-rå

$\begin{array}{llll}\dot{3} & \dot{4} & \dot{2} & 3\end{array}$

$J i-w a \quad R ̊ a-j a$

\section{c. Bagian Tiga}

Bagian tiga diawali dengan melodi piano yang dibunyikan secara ritmis, selanjutnya dimasuki semacam pathetan vokal putra dan putri yang menggunakan pola canon.

$$
\begin{aligned}
& \text { Piano } \\
& \mathrm{Cm}_{-} \cdot 3 \cdot 5 \cdot \quad \cdot \quad 3 \quad \cdot \quad 1 \|
\end{aligned}
$$


Cello $\|1 \ldots . \ldots 1 \ldots . \ldots 5\|$

Vokal 1

Vokal 2

\begin{tabular}{|c|c|c|c|c|c|c|c|c|}
\hline & $\begin{array}{ll}6 & 4\end{array}$ & 2 & 1 & 1 & 2 & 4 & 6 & 5 \\
\hline & $n \stackrel{a}{a} \quad c \stackrel{a}{-}$ & $r a ̊-$ & 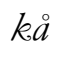 & $K a$ & rå & $c a ̊$ & $n \dot{a}-$ & 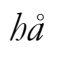 \\
\hline 1 & 2 & 6 & 5 & 5 & 6 & 4 & 2 & 1 \\
\hline & $t a ̊-s a ̊-$ & & - lå & Là & $w a ̊$ & 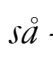 & tå & \\
\hline 5 & 4 & 2 & 1 & 1 & 2 & 4 & 6 & 5 \\
\hline & $d h \stackrel{\circ}{-}-j a ̊$ & & $-n y a ̊$ & Nya & $-y a$ & $-j \stackrel{\circ}{a}-$ & $d$ & \\
\hline 1 & 4 & 6 & (5) & 5 & 6 & 4 & 2 & \\
\hline
\end{tabular}

Pathetan vokal disajikan satu rambahan, setelah selesai disusul dengan piano, setelah ketukan keempat masuk vokal seperti di bawah ini.

$$
\begin{aligned}
& \text { Piano } \\
& \|\cdot \mathrm{Cm} \cdot \mathrm{Cm}\| \\
& \mathrm{Cm} \text {. } \mathrm{Cm} \text {. } \\
& \text { Cello } \| \begin{array}{llllllll||}
1 & 5 & \overline{45} & . & 1 & 5 & \overline{45}
\end{array} \\
& \text { Piano } \\
& \| \overline{56 \overline{421}} \quad \overline{12} \overline{465} \quad \overline{12} \overline{46} \cdot \overline{5642} . \\
& \overline{564} \quad \overline{124} \quad \overline{12} \quad \overline{56} \\
& \begin{array}{lllllll}
\overline{56} & \overline{42} & \overline{11} & \overline{24} & \overline{65} & \overline{64} & \overline{1}(2)
\end{array}
\end{aligned}
$$


Vokal di atas disajikan satu rambahan dengan menggunakan pola imbal, satu dan dua rambahan disajikan dengan bergantian, kemudian rambahan ketiga disajikan dengan cara koor.

\section{d. Bagian Empat}

Bagian empat diawali vokal putra dengan menyajikan menggunakan suara yang besar, lalu disusul vokal tunggal putri.

Vokal Putra
Kå rå cå nå hå
La wa sà tå då
Nyå yå jå dhå på
Ngå thå bå gå må
Vokal Putri

Gung se rah yu

Ha sas ing ta bu

Mige bar ning

rip a ti kèng

Sam ram paké

Vokal di atas disajikan dua kali rambahan, lalu disusul vokal putra dengan seperti menyuruh dan dijawab oleh vokal putri.
Vokal Putra
Vokal putri
Huuuusssss........sah
yik yik yik yik yik yik yik.

\section{e. Bagian Lima}

Bagian lima diawali dengan melodi piano dan cello disajikan tiga rambaban, pada rambahan ketiga lalu vokal putra dan vokal putri masuk.

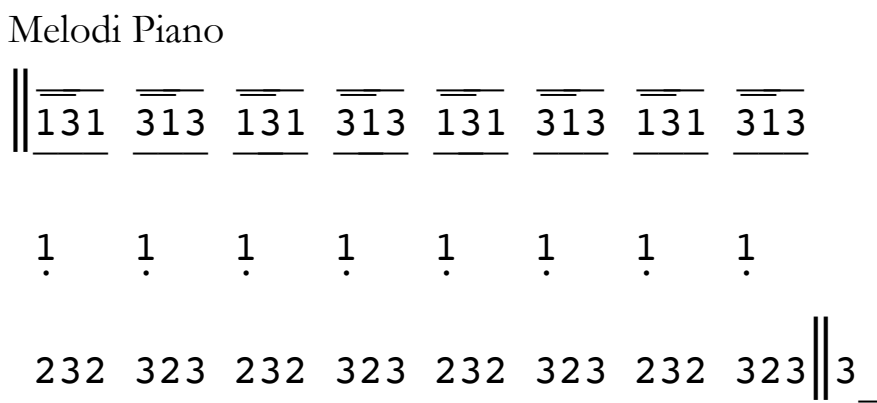

\section{$\begin{array}{llllllll}2 & 2 & 2 & 2 & 2 & 2 & 2 & 2\end{array}$}

Masuk vokal 


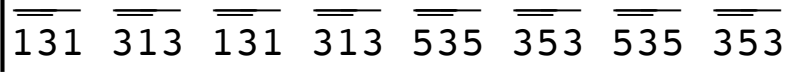

$\begin{array}{llllllll}1 & 5 & 1 & 5 & 1 & 5 & 1 & 5\end{array}$

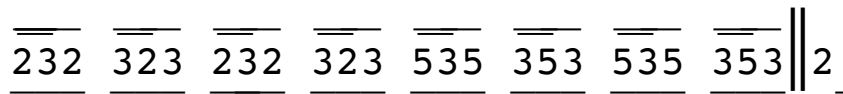

$\begin{array}{llllllll}2 & 6 & 2 & 6 & 2 & 6 & 2 & 6\end{array}$

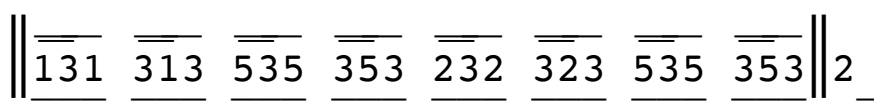

$\begin{array}{llllllll}1 & 5 & 1 & 5 & 2 & 6 & 2 & 6\end{array}$

Gong

$\| \cdot \cdot \cdot \cdot \cdot \cdot \cdot 2$ •

• $\cdot$ • • • (2)

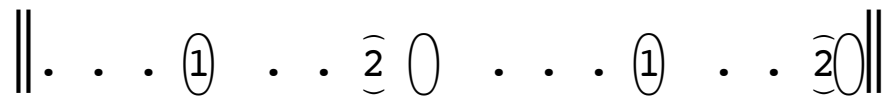

Vokal 1 putri

\begin{tabular}{||llllllll}
3 & 1 & 3 & 5 & 3 & 5 & 3 & 2
\end{tabular}

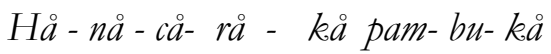

$\begin{array}{llllllll}3 & 2 & 3 & 5 & 3 & 5 & 3 & 1\end{array}$

sung sas-mi- tå sung sas-mi-tå

Vokal 2 putri

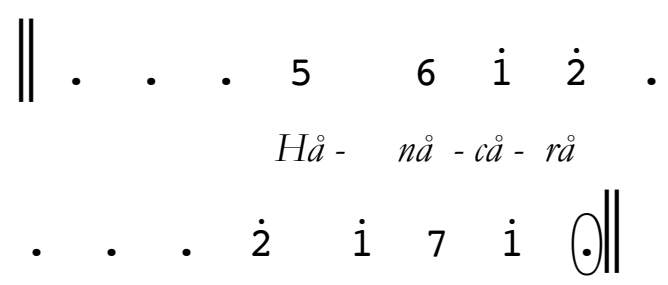


Vokal 2 putra

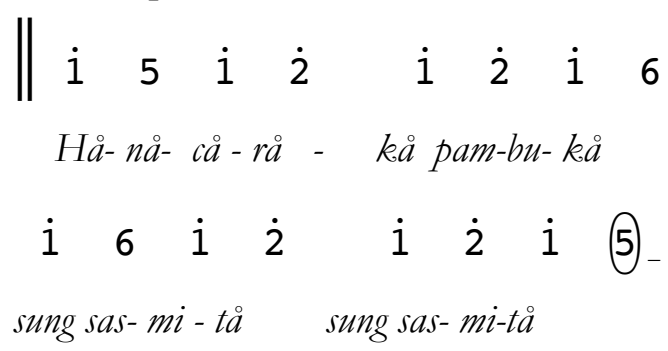

Pola di atas disajikan enam rambahan, dua kali rambahan dengan tempo lambat 4/4, lalu dua rambahan dengan tampo cepat 8/8, satu kali rambahan dengan tempo lambat, dan satu kali rambahan tempo cepat.

\section{f. bagian Enam}

Bagian ini diawali dengan vokal tunggal putri dan vokal tunggal putra yang kemudian disusul oleh piano.

$$
\begin{aligned}
& \| \cdot \underbrace{5 \quad 6}_{I-b u} 1 \quad \cdot \underbrace{5 \quad 6}_{b u-m i} 1 \\
& \begin{array}{llllll}
b_{b} & 6 & 1 & 5 & 6 & 4 \\
a & & a & -k a-s a ̊
\end{array} \\
& \text { - } 4254 \quad 5 \quad \underbrace{\overline{6 i}} \underbrace{\overline{65}} 4 \\
& \text { Dé-dé kang wu-jud cab-yå } \\
& \begin{array}{llllllll}
2 & 4 & 5 & 6 & 5 & \overline{64} & 2 & 1
\end{array} \\
& \text { no-ra si-nan-dha-ngan lå-rå } \\
& \text { Overtune } \quad \searrow \begin{array}{lllll}
5 & 6 & 2 & (3) & \text { pi-ran pa- } t i
\end{array} \\
& \text {-. } \overline{56} i \cdot . \overline{16} \\
& I-b u \quad b u \text { - }
\end{aligned}
$$




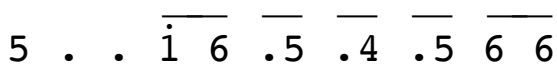

$$
\begin{aligned}
& \text { mi bå-på å-nå ing a-kå- } \\
& 6 . \quad 4 \quad 24 \quad 5 \overline{6 i} \\
& \text { så dé - dékang wu-jud } \\
& \overline{65} 4 \cdot \overline{12} \quad \overline{45} \quad \overline{65} \quad \overline{6 \quad 1}(5) \\
& \text { cab-yå no-ra si-nan-dha-ngan ing lå-rå } \\
& \text { Overtune } \ \begin{array}{llllllll}
1 & 2 & \overline{4} & 5 & \overline{6} & 5 & \overline{6} & \dot{2}
\end{array} \\
& \text { yek-ti kèng ke-sam-pi-ran pa-ti }
\end{aligned}
$$

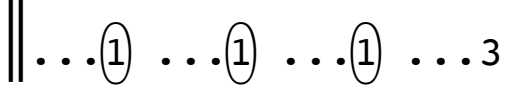

$$
\begin{aligned}
& \ldots 3 \quad \ldots 3 \quad \ldots 55 \quad \ldots .9 \|_{2}
\end{aligned}
$$

Overtune

_D\#m...D\#m...D\#m...G\#m...G\#m...

G\#m...G\#m...b...Cm..._ (kembali ke Cm 1x)

Gong

$$
\begin{aligned}
& \mid \ldots \text { (2) } \ldots \text { (2) } \ldots 5
\end{aligned}
$$

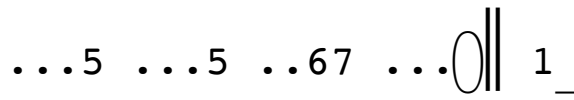

Vokal 1

$$
\begin{aligned}
& \| \cdot \underbrace{7 \mathrm{Z}}_{I-b u} 3 \quad \cdot \underbrace{7 \mathrm{Z}}_{b u-m i} 3 \\
& \text { - } \begin{array}{lllll}
78 & 3 & .7
\end{array}
\end{aligned}
$$

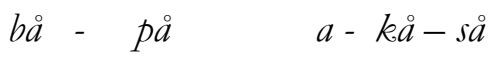


$\mathrm{Vi}$

Rudi Yatmoko (Gangsa Aksara......)

pp. $49-73$

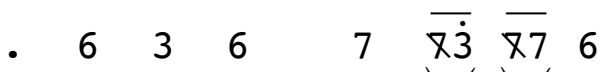

$$
\begin{aligned}
& \text { Dé-dé kang wu-jud cab-yå } \\
& \begin{array}{llllllll}
3 & 6 & 7 & \times & 7 & 6 & \times & 5
\end{array} \\
& \text { no-ra si-nan dha-ngan lå-rå }
\end{aligned}
$$

Vokal 2

$$
\begin{aligned}
& \text {.. } \underbrace{\overline{3}}_{I \overline{7}} \cdot . \quad \overline{\overline{38}}
\end{aligned}
$$

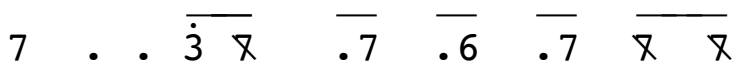

$$
\begin{aligned}
& \text { mi bå-på å-na ing a-kå- } \\
& \begin{array}{lllllllll} 
& \cdot & 6 & 3 & 6 & 7 & \overline{8 \dot{3}} & \overline{87} & 6
\end{array} \\
& \text { så dé - dékang wu-jud cah-yå } \\
& \text {. } \overline{38} \overline{67} \overline{\nabla 7} \overline{68}(5) \\
& \text { no-ra si-nan-da-ngan ing lå-rå }
\end{aligned}
$$

Pola di atas disajikan empat kali awal. Setelah rambahan keempat selesai lalu rambahan, satu kali vokal tunggal putri dan masuk vokal yang sama tetapi dengan putra, lalu satu kali vokal koor putra dan putri, menggunakan nada slendro dua kali rambaban kemudian satu kali rambahan dengan pola nada sebagai berikut overtune, dan satu kali rambahan kembali ke nada

$$
\begin{aligned}
& \| \cdot \underbrace{5 \quad 6}_{I} \underbrace{}_{-b u} \quad \cdot \underbrace{5 \quad 6}_{b u}{ }_{m i} \\
& \text { - } \begin{array}{lllllll}
5 & 6 & 1 & & 5 & 6 & 3
\end{array}
\end{aligned}
$$

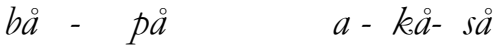

$$
\begin{aligned}
& \text { - } 32355 \overline{6 i} \overline{65} 3 \\
& \text { Dé-dé kang wu-jud cah-yå }
\end{aligned}
$$




$$
\begin{aligned}
& \begin{array}{llllllll}
2 & 3 & 5 & 6 & 5 & \overline{63} & 2 & 1
\end{array} \\
& \text { no-ra si-nan dha-ngan lå-rå } \\
& \text { Vokal } 2 \\
& \text { - } \cdot \underbrace{\overline{56}}_{I-} i \cdot \underbrace{\bar{i}}_{b u-m i} 5 \\
& \text {. . } \begin{array}{llllll}
\bar{i} 6 & \overline{.5} & \overline{.3} & \overline{.5} & \overline{66}
\end{array} \\
& \text { bå-på å- nå ing å-kå- } \\
& \text { 6. } .313 \quad 5 \quad 5 \quad \overline{6 i} \\
& \text { så dé - dékang wu-jud } \\
& \overline{65} 3 \cdot \overline{12} \overline{35} \overline{65} \overline{6 \text { i }} \text { (5) } \\
& \text { cah-yå no-ra si- nan-dha-ngan ing lå-rå } \\
& \text { Piano } \\
& { }_{-} \text {C...C...C...F...F...F...Dm...G...C... } 2 x \\
& \text { Gong } \\
& \text { \#i5i. isi. isi. i563 } \\
& \text { 636. 636. 636. i5i. } \|_{1}
\end{aligned}
$$

\section{g. Bagian Tujuh}

Pada bagian ini diawali dengan melodi piano dan cello dua kali rambahan, setelah selesai kemudian masuk vokal tunggal putri.

$$
\begin{aligned}
& \| \overline{i 654.5 \overline{64}} \overline{i 654.5 \overline{64}}- \\
& \text { i } 6 \overline{54} \overline{.5} \overline{64} 3.2 \cdot \| 2 x \\
& 1 \quad \underbrace{45} \quad \begin{array}{lllll}
7 i & 3 & 5 & 4
\end{array} \\
& \text { Ho bo bo bo bo na-dyan }
\end{aligned}
$$


$\mathrm{Vi}$

Rudi Yatmoko (Gangsa Aksara......)

pp. $49-73$

$\begin{array}{llllllll}5 & 6 & \mathrm{i} & 4 & 3 & 4 & 6 & 5\end{array}$

si-na-wang mu-bung sa-yek-ti

$7 i \quad$ i)

nyå - tå

Setelah vokal putri selesai sampai kata "nyata", lalu vokal putra dan putri masuk pada vokal dengan pola sebagai berikut.

$$
\begin{aligned}
& \text { Vokal }
\end{aligned}
$$

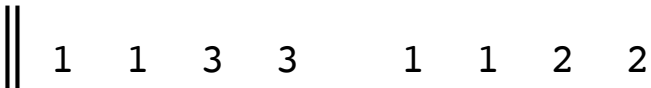

$$
\begin{aligned}
& \text { Ha-na-ning ti- tab wi-wå-bå } \\
& \begin{array}{llllllll}
1 & 6 & \cdot & 5 & 6 & 1 & 6 & 1
\end{array} \\
& \text { rå-så wus ka-sa-ri-rå } \\
& \begin{array}{llllllll}
1 & 1 & 3 & 3 & 1 & 1 & 2 & 2
\end{array} \\
& \text { Ha-na-ning ti- } \quad \text { tab } w i-w a ̊-b a \\
& \begin{array}{llllllll}
1 & 6 & \cdot & 5 & 6 & 1 & 6 & 1
\end{array} \\
& \text { rå-så wus ka-sa-ri-rå } \\
& 45 \cdot 34565 \\
& \text { No-ra ki-nu-dang } i-r a ̊ \\
& \overline{65} 4 \cdot 53 \cdot \overline{72}(1) \\
& \text { cå-rå cik bèn mur-cå } \\
& \text { Gong }
\end{aligned}
$$

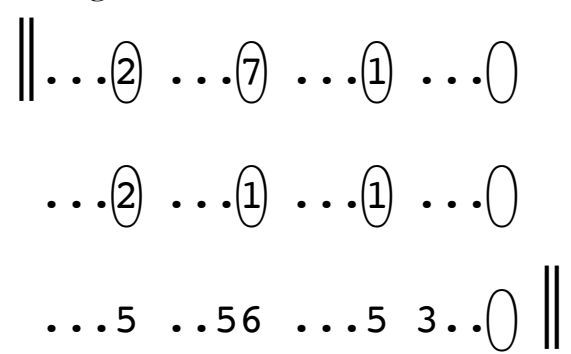


Pola di atas disajikan berulang-ulang hingga vokal tunggal putri selesai, vokal tunggal putri disajikan secara tegas dan bebas. Pola vokal tunggal putri seperti notasi di bawah ini.

$$
\begin{aligned}
& \begin{array}{llllll}
5 & 5 & 45 & 3 & 4 & 1
\end{array} \\
& \text { No - ra ku - rang wu-lang } \\
& \begin{array}{llllllllll}
4 & 4 & 6 & 6 & 4 & 4 & 5 & 5 & 4 & 4
\end{array} \\
& \text { wu-ruk pain-cå dha-wuh ja-gad yek-ti } \\
& \begin{array}{llllllll}
3 & 3 & 2 & 2 & 7 & 7 & 1 & \\
1 \ldots & \ldots
\end{array} \\
& \text { La-mun ge-lem ang-la-kå- ni }
\end{aligned}
$$

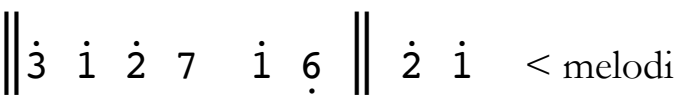

$$
\begin{aligned}
& \text { Se-ja-ti -ning darmå tå-må }
\end{aligned}
$$

\section{h. Bagian Delapan}

Pada bagian terakhir ini vokal lebih dominan menggunakan teknik unisono, bagian ini diawali dengan melodi piano yang menjadi jalinan dari bagian sebelumnya satu kali rambahan kemudian langsung masuk vokal putra dan putri secara cepat.

\section{Simpulan}

Aksara Jawa dapat menjadi medium untuk dijadikan sebuah karya, karena aksara tersebut masih dipelajari sampai saat ini. Berdasarkan cerita lahirnya aksara Jawa, maka makna yang terkandung di dalam aksara tersebut dapat dipetakan menjadi empat makna yaitu: (1) utusan; (2) saling bertengkar; (3) sama kuatnya; dan (4) kematian. Makna tersebut diambil dari perkalimat aksara (hanacaraka, datasawala, padajayanya, dan magabanthanga) tidak diambil dari makna perhuruf aksara.

Sifat yang terkandung dalam makna utusan adalah agung dan berwibawa, maka dengan pijakan sifat tersebut akan diimplementasikan kedalam musik yang berwatak agung dan berwibawa untuk menggambarkan seorang yang menjadi utusan. Sedangkan sifat di dalam makna saling bertengkar dan sama kuatnya adalah nafsu dan amarah, kedua sifat tersebut akan dijadikan dalam satu bagian yang memiliki sifat nafsu amarah. Pada bagian kematian memiliki sifat kesedihan yang mendalam, hal tersebut juga menjadi pijakan dalam membuat karya ini. 
Sifat-sifat atau makna yang terkandung dalam aksara tersebut diolah dan diimplementasikan pada komposisi musik dalam karya "Gangsa Aksara”. Adapun komposisi musik tersebut: "Cundhaka", "Pralaga", dan "Pralaya".

Penyusunan karya "Gangsa Aksara" menggunakan tiga tahapan, yaitu: penyusunan gagasan isi, penyusunan garapan, dan penuangan ide garapan. Pada tahap penyusunan gagasan pengkarya melakukan observasi dengan membaca buku, perenungan, dan berdiskusi. Pada tahap penyusunan ide garap pengkarya mulai menetukan instrumen dan memikirkan garap yang terdapat pada masing-masing bagian komposisi, dengan mengacu sifat atau karakter yang ingin diwujudkan. Pada tahap penuangan pengkarya melakukan latihan rutin, tahapan dalam latian sebagai berikut: eksplorasi teknik dan pola permainan instrumen, pencarian melodi melalui eksplorasi, penyusunan bagian-bagian komposisi dan mecari sambung rapet antara bagian komposisi. Setelah bagian komposisi sudah terangkai, maka dilanjutkan untuk mengolah tempo dan volume, dan menekankan rasa pada setiap bagian musiknya. Tahap akhir adalah evaluasi.

\section{E. Daftar Pustaka}

Benamou, Marc. 1998. Rasa in Javanese Musical Aesthetics. USA: UMI.
Danesi, Marcel. 2010. Pesan, Tanda, dan Makna. Yogyakarta: Jalasutra.

Djohan. 2003. Psikologi Musik. Yogyakarta: Buku Baik.

Endraswara, Suwardi. 2006. Filsafat Kejawen Dalam Aksara Jawa. Jogjakarta: Gelombang Pasang.

Hapsari Dwi, Fani. 2016. “Aksara Jawa Sebagai Ide Penciptaan Karya Tari Aksara Tubuh Oleh Boby Ari Setiawan." Surakarta: ISI Surakarta.

Hutomo. 1987. "Cerita Kentrung: Klasifikasi Model Dari Ben-Amos," 29, , 3-19.

Marduwiyoto, Lasman. 1981. Manikmaya II. Jakarta: Departemen Pendidikan dan Kebudayaan.

McNeill, J Rhoderick. 2000. Sejarab Musik. Jakarta: Gunung Mulia.

Padnobo, Cokro Halintar. 2016. "Pertunjukan Wayang Kulit Lakon Aji Saka Sajian Purbo Asmoro Dalam Perspektif Sanggit Dan Garap.” Surakarta: ISI Surakarta.

Sukerta, Pande Made. 2011. Metode Penyusunan Karya Musik: Sebuah Alternatif. Surakarta: ISI Press.

\section{DISKOGRAFI}

Ari Setiawan, Bobby. 2012. Hanacaraka. Surakarta: AVI FACP. https://www.youtube.com/watch?v $=$ n RWd0TzByGI

Candra Rini, Peni. 2018. Timur. CD. Sukoharjo: Sentana Art.

Pambayun, Wahyu Thoyyib. 2018. Kalatidha. CD. Surakarta: ISI Surakarta. 
Supanggah, Rahayu. 2010. Music Of Opera Jawa. DVD. Surakarta: Garasi Seni Benawa.

Suwardi, A.L. 2014. Nunggak Semi. Surakarta: Bukan Musik Biasa. https://www.youtube.com/watch?v=5 oHtr-duAXY.
Widodo, Sri Eko. 2014. Swub Rep Datapitana. DVD. Surakarta: ISI Surakarta.

Moore, R., Lopes, J., 1999. Paper templates. In Template'06, 1st International Conference on Template Production.

Smith, J., 1998. The book, The publishing company. London, $2^{\text {nd }}$ edition. 